\title{
Teknologi dan Teknik Sistem Terdistribusi Pervasif dalam Bidang Logistik: Studi Literatur Sistematis
}

\author{
Egia Rosi Subhiyakto ${ }^{1}$, Danang Wahyu Utomo ${ }^{2}$, Prajanto Wahyu Adi $^{3}$ \\ Fakultas Ilmu Komputer, Universitas Dian Nuswantoro \\ Jl. Nakula I No. 5-11 Semarang, Jawa Tengah 50131 \\ E-mail: egia@dsn.dinus.ac.id ${ }^{1}$,danang.wu@dsn.dinus.ac.id ${ }^{2}$, prajanto@dsn.dinus.ac.id ${ }^{3}$ \\ Masuk: 12 Mei 2015; Direvisi: 8 Juni 2015; 11 Agustus 2015; Diterima: 14 Agustus 2015
}

\begin{abstract}
Distributed pervasive system is part of distributed system that can be accessed anytime, anywhere, anybody, and anyone. In the part of logistics, supply chain has problems such as real time visibility, materials and products track and trace, and response time for huge data stream processed to automating control smart package. Increasingly advanced technology needed technology to monitor the transport chain with smart thing and some techniques needed to be used to increase performance of the technology. In this paper will study technologies are using in pervasive system domain of logistics, especially technologies to monitor transport chain. Besides, presented several techniques used to improve performance of the technologies. In this paper found some technologies such as RFID, Wireless Sensor Networks (WSN), and hybrid technology used in pervasive system domain of logistics. Also found some techniques to improve performance like smoothing method, multi threshold algorithm, and kalman filter technique. Based on literature can be conclude that some techniques can improve performance of technologies.
\end{abstract}

Keywords: Distribute Pervasive System, Logistic, Systematic Literature Review

\begin{abstract}
Abstrak. Sistem terdistribusi pervasif merupakan bagian dari sistem terdistribusi yang dapat diakses kapan saja, di mana saja, dan oleh siapa saja. Di bidang logistik, rantai pasokan memiliki masalah dalam hal visibilitas real time, pelacakan bahan dan produk, serta waktu respon untuk dalam proses data untuk mengotomatisasi kontrol paket cerdas. Semakin berkembangnya teknologi, semakin canggih teknologi yang digunakan untuk memantau rantai transportasi dengan cerdas dan beberapa teknik diperlukan untuk meningkatkan kinerja teknologi. Dalam makalah ini akan dibahas mengenai teknologi yang digunakan dalam sistem terdistribusi pervasif untuk bidang logistik, khususnya teknologi untuk memantau rantai pasokan. Selain itu, disajikan beberapa teknik yang digunakan untuk meningkatkan kinerja teknologi. Dalam makalah ini ditemukan beberapa teknologi seperti RFID, Wireless Sensor Networks, dan teknologi gabungan yang digunakan untuk bidang logistik. Juga ditemukan beberapa teknik untuk meningkatkan kinerja seperti metode smoothing, teknik algoritma multitreshold, dan teknik kalman filter. Berdasarkan literatur dapat disimpulkan bahwa beberapa teknik dapat meningkatkan kinerja teknologi.
\end{abstract}

Kata Kunci: Sistem Terdistribusi Pervasif, Logistik, Studi Literatur Sistematis

\section{Pendahuluan}

Komputasi pervasif atau meresap memiliki tujuan untuk membuat lingkungan cerdas yang tertanam sistem dengan perangkat jaringan yang mendukung sehingga pengguna manusia dapat menggunakan akses layanan dengan mulus (Raychoudhury, dkk., 2013). Selain itu, komputasi pervasif dapat mewujudkan untuk menangkap informasi yang diberikan oleh lingkungan terintegrasi dengan sensor baik melalui instruksi langsung atau beberapa instruksi (Ye, dkk., 2012). Lingkungan komputasi pervasif terdiri dari empat bagian seperti perangkat atau alat, middleware, aplikasi dan jaringan (Saha, dkk., 2003). Dalam Ferscha (2012) 
dijelaskan bahwa komputasi pervasif memiliki tiga generasi dengan masing-masing karakteristiknya. Pertama, pada 1990 sampai awal tahun 2000 memiliki karakteristik keterhubungan (by connectedness). Kedua, dari awal 2000 sampai pertengahan 2000 memiliki karakteristik pengetahuan (by awareness). Dan generasi ketiga dari pertengahan 2000 sampai sekarang memiliki karakteristik kecerdasan (by smartness). Heterogenitas di tingkat sistem, interkoneksi yang kompleks, dan pola interaksi dalam sistem jaringan dan konektivitas jaringan yang terbatas menjadi alasan sistem pervasif yang kompleks untuk digunakan (Chandrasekaran, dkk., 2010).

\section{Rumusan Masalah}

Health monitoring dan assistance, gaming, smart home, serta transportasi dan logistik merupakan aplikasi dalam komputasi pervasif (Marinagi, dkk., 2013). Di bagian logistik, rantai pasokan memiliki masalah seperti visibilitas real time, pelacakan bahan dan produk, serta waktu respon untuk aliran data yang besar diproses untuk mengotomatisasi kontrol paket cerdas (Marinagi, dkk., 2013). Saat ini teknologi yang dibutuhkan semakin canggih untuk memantau rantai transportasi dengan hal-hal yang cerdas. Dalam perkembangannya, beberapa teknik juga perlu digunakan untuk meningkatkan kinerja teknologi. Teknologi yang digunakan dalam sistem pervasif terutama domain logistik memiliki kelemahan dalam implementasinya, sehingga beberapa teknik dibutuhkan untuk meningkatkan kinerja teknologi.

\section{Metode Review}

\subsection{Pendahuluan}

Kitchenham, dkk. (2007) menjelaskan bahwa studi literatur sistematis merupakan sebuah proses mengidentifikasi, mengevaluasi dan menafsirkan semua bukti penelitian untuk menjawab pertanyaan penelitian yang meliputi cakupan topik atau fenomena yang menarik. Terdapat dua fokus dalam studi ini. Keduanya membahas tentang teknologi dan teknik untuk meningkatkan kinerja dari teknologi yang berhubungan dengan komputasi pervasif dalam domain logistik. Berikut adalah fokus tersebut: (1) Teknologi yang digunakan untuk melakukan pemantauan rantai transportasi, (2) Teknik yang digunakan untuk meningkatkan kinerja teknologi sistem pervasif dalam domain logistik.

\subsection{Identifikasi literatur yang relevan}

Untuk mencari paper atau literatur yang mencakup bahasan mengikuti tahapan sebagai berikut: (1) Mendaftar kata kunci. (2) Menggunakan kata alternatif/sinonim. (3) Menyaring hasil pencarian berdasarkan jurnal/publikasi konferensi/buku/pekerjaan terkait/studi yang relevan. (3) Menggunakan Booloean OR dan AND. Contoh string pencarian: pervasive logistics (application OR systems OR prototype) (effective OR efficient) (techniques OR technologies) AND (transport chain OR supply chain) track and trace AND (products OR material logistics). Dalam studi ini, pencarian literatur utama menggunakan enam database online yakni Scopus, Science Direct, IEEE Xplore, ACM digital library, Emerald, dan Scirus.

\subsection{Pemilihan penelitian}

Pemilihan penelitian yang dilakukan untuk mendapatkan data dan informasi dari pencarian literatur termasuk studi. Pencarian literatur termasuk studi ini diterbitkan dalam tahun 2003 sampai 2013. Terdapat dua kriteria untuk pemilihan penelitian termasuk kriteria inklusi dan kriteria eksklusi. Kriteria inklusi: (1) Studi tentang komputasi pervasif dalam domain logistik. (2) Studi yang membahas tentang teknologi yang digunakan dalam sistem terdistribusi pervasif. (3) Studi yang membahas teknik untuk meningkatkan kinerja teknologi. Kriteria eksklusi: (1) Paper membahas teknologi untuk sistem terdistribusi pervasif. (2) Paper membahas teknik untuk meningkatkan kinerja teknologi, tetapi tidak untuk pervasif. (3) Paper tentang komputasi pervasif, tetapi tidak dalam domain logistik. 


\subsection{Ekstraksi Data dan Studi Penilaian Kualitas}

Ekstraksi data yang digunakan untuk mengukur kualitas penelitian. Terdapat checklist kualitas yang dirancang untuk mengukur kualitas berdasarkan kriteria inklusi dan eksklusi. Kriteria inklusi dan eksklusi membahas studi tentang teknologi dalam sistem terdistribusi pervasif dan teknik yang digunakan untuk meningkatkan kinerja teknologi. Tabel 1 menunjukkan checklist kualitas studi berdasarkan kriteria inklusi dan eksklusi.

Tabel 1. Kriteria pemilihan paper

\begin{tabular}{lc}
\multicolumn{1}{c}{ Item } & Jawaban \\
\hline 1. Apakah penelitian membahas teknologi? & Ya/ \\
Sebagai contoh RFID technology, wireless sensor networks, dll & Tidak/ \\
(Wang, dkk., 2009), (Xu, dkk., 2010), (Sardroud, 2012), (Cao, & Sebagian \\
dkk., 2011), (Gholami, dkk., 2012), (Woo, dkk., 2009), (Ruta, & \\
dkk., 2008), (Martínez-Sala, dkk., 2009), (He, dkk., 2009), & \\
(Zhang, dkk., 2008), (Doss, dkk., 2012), (Marchese, dkk., & \\
2010), (Zöller, dkk., 2011) & Ya/ \\
\hline 2. Apakah penelitian membahas teknik yang digunakan untuk & Tidak/ \\
meningkatkan kinerja teknologi? & Sebagian \\
Sebagai contoh, Neural based technique, Kalman filter & \\
technique, Trilateration based technique, dll & \\
(Zöller, dkk., 2011), (Zu, dkk., 2010), (Ruta, dkk., 2008), & \\
(Gholami, dkk., 2012) & Ya f \\
\hline 3. Apakah terdapat paper yang menyajikan penggunaan & Tidakt \\
teknologi gabungan? & Sebagian \\
\hline
\end{tabular}

\section{Hasil sintetis penelitian}

\subsection{Pendahuluan}

Sintesis dari penelitian ini akan disajikan dalam bagian ini. Seperti yang telah dijelaskan di atas ada enam database online (Scopus, Science Direct, IEEE Xplore, ACM Digital Library, Emerald, dan Scirus) yang menjadi sumber literatur. Kata kunci utama yang digunakan adalah "sistem pervasif dalam domain logistik". Kriteria inklusi dan eksklusi digunakan untuk menyaring literatur yang mencakup penelitian ini. Pada bagian berikut disajikan hasil untuk tinjauan literatur sistematis untuk menjawab semua pertanyaan penelitian dan sub pertanyaan.

\subsection{Distribusi Publikasi}

Dalam studi literatur ini, terdapat 27 makalah yang berhubungan dengan komputasi sistem terdistribusi pervasif. Distribusi makalah per tahun disajikan untuk melihat seberapa pentingnya teknologi dalam komputasi pervasif dari tahun ke tahun. Sajian singkat mengenai hal ini disajikan dalam Gambar 1 yang menunjukkan bahwa teknologi dalam bidang komputasi pervasif semakin meningkat jumlahnya dari tahun ke tahun.

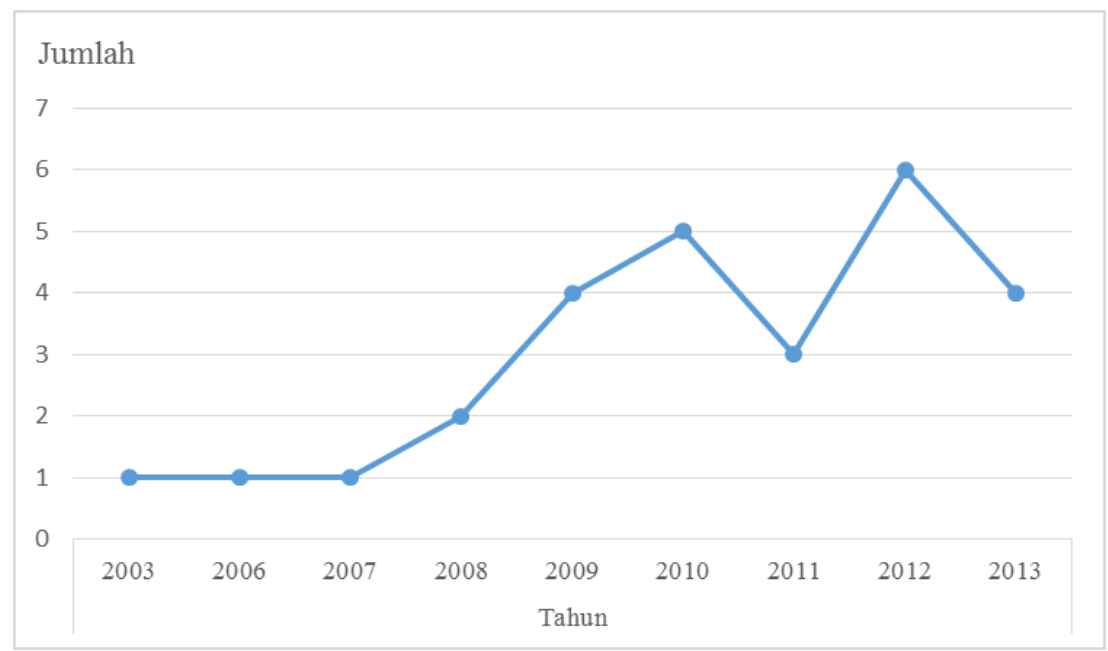

Gambar 1. Distribusi makalah dari tahun ke tahun 


\subsection{Parameter yang digunakan dalam Teknologi}

Dalam Tabel 2 disajikan teknologi beserta parameter yang digunakan. Terdapat parameter real time, response time, coordination system, local system, delay tolerant, temperature, power source, accuracy, dan data transmission.

Tabel 2. Teknologi dan parameter

\begin{tabular}{|c|c|c|c|c|}
\hline \multirow[t]{2}{*}{ No } & Teknologi & RFID & Wireless Sensor Networks & Hybrid Technology \\
\hline & Parameter & & & \\
\hline 1 & Real time & $\begin{array}{l}\text { (Wang, dkk., 2009) (Xu, } \\
\text { dkk., 2010) } \quad \text { (Sardroud, } \\
\text { 2012) (Cao, dkk., 2011) }\end{array}$ & $\begin{array}{l}\text { (Gholami, dkk., 2012) } \\
\text { (Cao, dkk., 2011) } \\
\text { (Woo, } \\
\text { dkk., 2009) }\end{array}$ & (Zhang, dkk., 2006) \\
\hline 2 & Response time & (Ruta, dkk., 2008) & & \\
\hline 3 & Coordination system & $\begin{array}{l}\text { (Martínez-Sala, dkk., 2009) } \\
\text { (Sardroud, 2012) }\end{array}$ & (Woo, dkk., 2009) & (He, dkk. 2009) \\
\hline 4 & Local system & ( Cao, dkk., 2011) & $\begin{array}{l}\text { Cao, dkk., 2011) (Woo, } \\
\text { dkk., 2009) }\end{array}$ & (He, dkk. 2009) \\
\hline 5 & Delay tolerant/ estimation & $\begin{array}{l}\text { (Zhang, dkk., 2008) (Doss, } \\
\text { dkk., 2012) }\end{array}$ & $\begin{array}{lll}\text { Marchese, } & \text { dkk., 2010) } \\
(\text { Zhang, dkk., 2008) } & \\
\end{array}$ & (He, dkk. 2009) \\
\hline 6 & Temperature & (Martínez-Sala, dkk., 2009) & & \\
\hline 7 & Power source & (Xu, dkk., 2010) & & \\
\hline 8 & Accuracy & (Sardroud, 2012) & (Woo, dkk., 2009) & \\
\hline 9 & Data transmission & $(\mathrm{Xu}, \mathrm{dkk} ., 2010)$ & (Zöller, dkk., 2011) & \\
\hline
\end{tabular}

Gambar 2 menyajikan pemetaan literatur berdasarkan penggunaan parameter dalam teknologi yang digunakan yakni RFID, WSN dan teknologi hybrid. Berdasarkan Gambar 2 didapatkan hasil bahwa penggunaan parameter real time digunakan dalam literatur untuk teknologi RFID sebanyak empat makalah $(14,8 \%)$, WSN tiga makalah $(11,1 \%)$, dan teknologi hybrid sebanyak satu makalah $(3,7 \%)$. Parameter coordination system untuk RFID dua makalah $(7,4 \%)$, WSN satu makalah(3,7\%), hybrid makalah $(7,4 \%)$, local system untuk RFID satu makalah $(3,7 \%)$, WSN dua makalah $(7,4 \%)$, hybrid satu makalah $(3,7 \%)$, parameter Delay tolerant/ estimation untuk teknologi RFID sebanyak dua makalah $(7,4 \%)$, WSN dua makalah $(7,4 \%)$ dan hybrid satu makalah (3,7\%). Dalam parameter accuracy jumlahnya sama dengan parameter data transmission dalam RFID sebanyak satu makalah $(3,7 \%)$ dan WSN satu makalah $(3,7 \%)$. Dalam beberapa literatur yang direview juga terdapat beberapa parameter yang hanya digunakan oleh teknologi RFID dan tidak digunakan dalam teknologi WSN maupun hybrid yakni parameter response time, temperature dan power source.

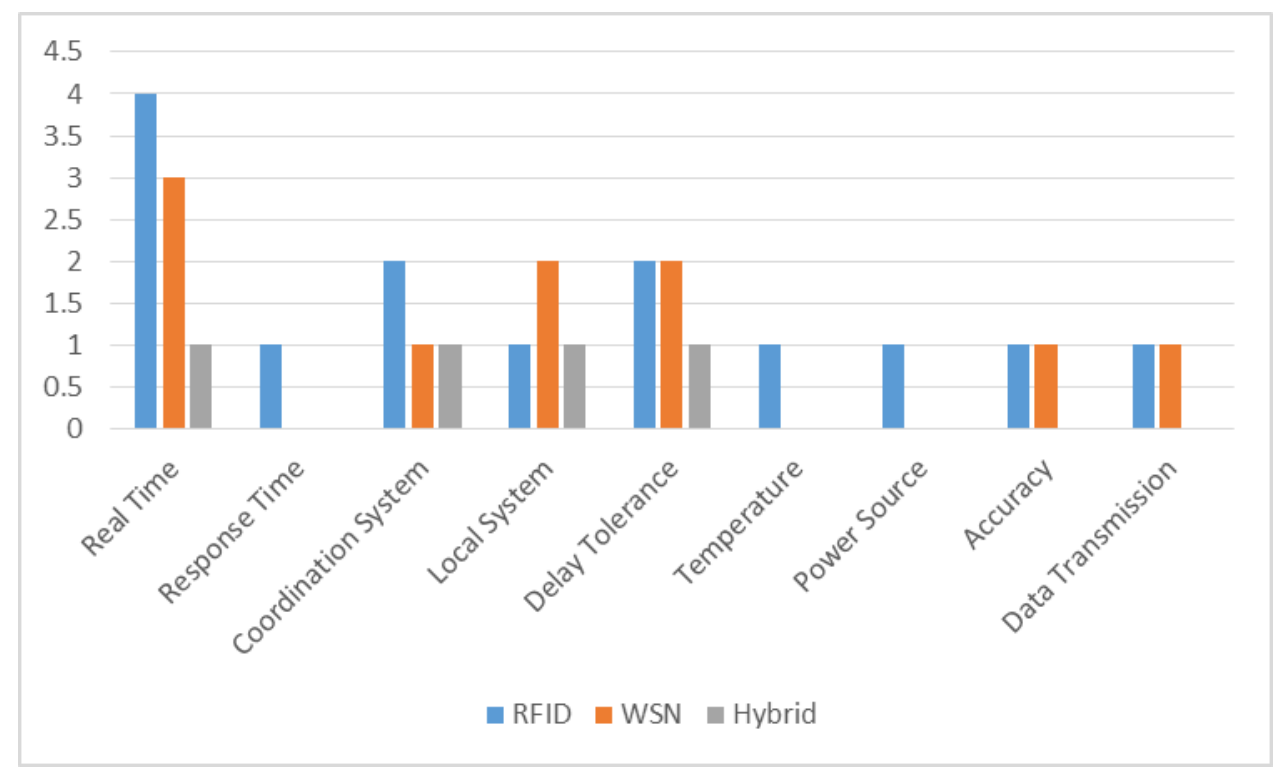

Gambar 2. Pemetaan literatur berdasarkan parameter dalam teknologi 


\subsection{Hasil Sintesis}

Berdasarkan Tabel 2 di atas didapatkan bahwa studi literatur sistematis sistem terdistribusi pervasif dalam domain logistik menggunakan tiga teknologi utama: RFID, Wireless sensor networks, dan Hybrid Technology.

\subsubsection{Teknologi RFID}

Dalam Marinagi, dkk. (2013) terdapat beberapa frekuensi yang dapat dioperasikan oleh sistem RFID seperti LF, HF, UHF, dan microwave. Untuk aplikasi pelacakan transportasi biasanya menggunakan UHF (Ultra High Frequency) yang mempunyai frekuensi 860-960 MHz. Dalam domain logistik, teknologi RFID dapat meningkatkan pengumpulan data secara akurat, kemampuan penyimpanan data, dan usaha manusia dapat dikurangi. Selain itu, teknologi RFID adalah teknologi yang efisien untuk melacak dan menelusuri produk.

\subsubsection{Wireless Sensor networks}

Teknologi sensor dapat digunakan untuk mengumpulkan, menentukan, dan memahami data di dunia nyata. Untuk proses mengontrol dan menilai kualitas produk dalam manufaktur dan logistik, teknologi sensor diadopsi. Suhu dan kelembaban adalah parameter sebagai alat ukur. Contoh aplikasi teknologi sensor yakni barcode scanner yang tertanam dalam keranjang belanja (Marinagi, dkk., 2013).

\subsubsection{Hybrid technology}

Hybrid technology atau teknologi gabungan merupakan kombinasi dari beberapa teknolgi seperti teknologi RFID dan Wireless Sensor Network untuk meningkatkan efektivitas. Zhang, dkk. (2006) menyajikan integrasi dari teknologi RFID dengan teknologi Wireless Sensor Networks (WSN).

\subsection{Teknologi yang paling sering digunakan untuk memantau rantai transportasi}

Berdasarkan hasil pemetaan literatur yang di review didapatkan bahwa RFID, Wireless Sensor system, dan kombinasi antara Wireless Sensor system dengan RFID (hybrid) adalah teknologi yang digunakan untuk memantau rantai transportasi. Studi yang membahas teknologi RFID berjumlah sekitar delapan penelitian (50\%), Wireless sensor network enam penelitian $(37,5 \%)$ dan dua penelitian (12,5\%) membahas penggabungan teknologi (hybrid). Jadi, dapat disimpulkan bahwa RFID (Radio Frequency IDentification) adalah teknologi yang paling sering digunakan untuk memantau rantai transportasi.

Visi komputasi meresap didasarkan pada gagasan bahwa komputer masa depan akan bergabung dengan lingkungan mereka. Radio Frequency Identification (RFID) dan Wireless Sensor Network (WSN) adalah dua komponen penting dari komputasi meresap, karena kedua teknologi dapat digunakan untuk kopling fisik dan dunia maya. Namun, RFID dan WSN hampir berada di bawah pembangunan di metode paralel, beberapa skema integrasi dan peluang terkait diselidiki secara rinci. Melalui analisis mendalam dari RFID dan WSN, tiga bentuk arsitektur sistem baru dalam Zhang, dkk. (2006) yang menggabungkan dua teknologi yang diusulkan dan kelayakannya beserta tantangannya. Dalam makalah tersebut diusulkan tiga bentuk yang berbeda dari arsitektur jaringan, yang memiliki fitur konsekuen sebagai node fungsional yang berbeda terintegrasi tag RFID atau pembaca dengan node sensor. Dalam kelas pertama integrasi membentuk stasiun pintar pembaca RFID campuran dan BTS WSN adalah faktor yang menentukan untuk seluruh sistem. BTS yang rumit dan mahal dan volume yang sangat besar yang juga membuat sulit untuk bergerak. Jika ada sesuatu yang salah dengan stasiun cerdas seluruh sistem akan memecah dan karena keandalan sistem menurun. Dibandingkan dengan stasiun cerdas, dua kelas terakhir dari integrasi menyediakan manajemen baru jauh lebih murah dan lebih fleksibel. Ini akan menjadi solusi efisiensi ketika kebutuhan real time tidak ketat dan data transmisi tidak sangat besar. Di sisi lain, jumlah transmisi data sangat besar atau bekerja real time kebutuhan untuk menyelesaikan pembaca RFID campuran dan penyebaran WSN base station akan sangat efektif. 
Dalam makalah Sardroud (2012) disajikan pendekatan baru untuk mengintegrasikan inovasi terbaru, yang menangani hal jelas untuk mengotomatisasi pelacakan dan pemantauan sumber daya konstruksi (misalnya bahan dan komponen), menggunakan sedikit atau tidak ada usaha manusia. Teknologi yang dipilih melibatkan penggunaan kombinasi GPS dan GSM teknologi dilengkapi dengan teknologi RFID untuk mendapatkan informasi real time dan informasi yang akurat tentang sumber daya. Informasi yang dikumpulkan kemudian dapat dibagi di antara semua pemain dalam konstruksi termasuk pihak hulu (misalnya pemasok bahan) dan pihak hilir (misalnya kontraktor). Penggunaan pelacakan otomatis yang canggih dan teknologi penyimpanan data dapat memberikan berwujud dan manfaat yang komprehensif dalam komunikasi dan pemanfaatan tenaga kerja, dan juga dapat sangat murah, solusi infrastruktur bebas untuk membentuk tulang punggung dari sistem manajemen sumber daya konstruksi (misalnya sistem manajemen bahan). Dalam pendekatan ini, kombinasi RFID, GPS, dan teknologi GSM, sebagai alat pengumpul data yang kuat, memungkinkan pengumpulan, penyimpanan, berbagi, dan penggunaan kembali data lapangan secara akurat, benar-benar, dan instan.

\subsection{Parameter yang digunakan untuk mengukur kinerja teknologi}

Parameter digunakan untuk mengukur efektivitas teknologi. Berdasarkan Tabel 2 di atas dalam studi ini dikelompokkan berdasarkan teknologi yang digunakan (RFID technology, Wireless sensor network, and hybrid technology) dan parameter yang menjadi alat ukur teknologi tersebut.

Dalam Zöller, dkk. (2011) ditemukan bahwa efisiensi biaya dan kepuasan pelanggan merupakan hal yang penting untuk dipertimbangkan dalam domain logistik. Transmisi data merupakan operasi yang paling mahal dalam hal konsumsi energi dan biaya. Kemudian dalam makalah tersebut diusulkan konsep penyaringan data lokal untuk mengurangi jumlah pengiriman data, dengan menggunakan algoritma multi-treshold untuk mendeteksi secara lokal. Dalam algoritma tersebut terdapat komponen sensor yang bertanggungjawab untuk menampilkan sampel sensor dan mendeteksi peristiwa yang relevan dan memastikan transmisi berlaku efisien dan mudah beradaptasi. Kontribusi dari penelitian tersebut adalah mendapatkan konsumsi energi yang hemat biaya dari jaringan sensor nirkabel logistik dan secara eksplisit memberikan manfaat secara real time. Hasil simulasi juga menunjukkan keuntungan yang lebih baik dengan algoritma multi-treshold dari segi transmisi data dan konsumsi energi.

Ruta, dkk. (2008) mengusulkan layanan mobile directory yang dirancang dengan menggunakan arsitektur dua tingkat yakni RFID digunakan pada field layer (terjadinya interkoneksi reader dan tag), sedangkan discovery layer memungkinkan komunikasi antara reader dan mobile host dalam konteks nirkabel dalam memainkan peran layanan direktori mobile. Hasilnya reader RFID digunakan untuk mendapatkan penjelasan semantik yang berasal dari tag diberbagai radio dan secara otomatis menangani permintaan penemuan layanan tanpa perantara kabel. Sedangkan dalam Zu, dkk. (2010) menggunakan metode smoothing untuk membangun data diukur asli untuk menurunkan kesalahan NLOS (Non Line of Sight Propagation). Kemudian algoritma genetika ditingkatkan diterapkan untuk memecahkan model nonlinear multi-dimensi juga. Hasil simulasi eksperimen menunjukkan kinerja yang baik. Hal ini dapat menangani skala besar dalam hal menunggu posisi target atribut data.

Sejumlah aplikasi di berbagai bidang seperti logistik, pengiriman kargo, dan transportasi melibatkan manajemen armada kendaraan yang diharapkan dapat melakukan perjalanan dengan lebih baik dengan rute dan jadwal yang tetap. Pembangunan jalan, kecelekaan dan kondisi tak terduga lainnya menyebabkan kendaraan menyimpang dari jadwal seharusnya. Pada saat yang sama, ada kebutuhan untuk infrastruktur sekitar kendaraan untuk terus mengetahui status sebenarnya dari kendaraan. Misalnya, tersedianya layar untuk mengetahui posisi bus dan kedatangan bus yang ditampilkan di halte. Hal tersebut menjadi tantangan mendasar sebagai pengetahuan dengan biaya minimal. Dalam makalah Tie , dkk. (2007) membahas tantangan yang berkaitan dengan pelacakan secara real time dan prediksi waktu perjalanan kendaraan menggunakan komunikasi nirkabel. Makalah ini menjelaskan 
masalah pelacakan dan prediksi dalam konteks perjalanan kendaraan yang dijadwalkan, dan mengidentifikasi tantangan utama. Meskipun pelacakan perjalanan kendaraan yang dijadwalkan memiliki potensi untuk menjadi lebih efisien daripada pelacakan kendaraan yang dilakukan perjalanan sepanjang rute yang tidak diketahui, requirements seringkali juga lebih tinggi. Sama berlaku untuk akurasi prediksi waktu tempuh. Tantangan utama yang terkait dengan ini dapat disimpulkan sebagai berikut: (1) algoritma prediksi harus bersaing dengan pengaruh faktor eksternal yang hanya diprediksi untuk berbagai tingkat, (2) kebijakan pembaruan harus dioptimalkan, dengan mempertimbangkan masalah domain, dan (3) semua parameter sistem harus dijaga dan diperbarui secara dinamis oleh sistem itu sendiri dalam menanggapi perilaku sistem saat ini.

Makalah Ricci, dkk. (2009) membahas pengembangan prosesor baseband dari pasif tag UHF-RFID. Perhatian khusus ditujukan untuk isu daya yang secara langsung membatasi kinerja tag. Beberapa teknik optimasi daya telah dibahas, mulai dari standar sel desain untuk sistem dan sirkuit detail. Transponder dilaksanakan mengeksploitasi teknologi $180 \mathrm{~nm}$. Sebuah perancangan sel aliran berdasarkan standar dipilih, dalam rangka untuk menyederhanakan migrasi ke node teknologi masa depan. Satu set sel berdedikasi standar telah dirancang, disesuaikan pada tegangan rendah, daya aplikasi yang terbatas. Integrasi dengan perangkat sensor juga dibahas, sehubungan dengan kedua standar antarmuka udara dan tingkat sirkuit. Uji fungsional dari arsitektur yang diusulkan telah dilakukan juga, melalui tes ekstensif beberapa chip sampel. Kepatuhan penuh dengan persyaratan standar telah dibuktikan. Kedua simulasi dan tes eksperimen mengkonfirmasi keabsahan pendekatan yang diusulkan, dan menyoroti angka kinerja yang luar biasa dari pelaksanaan tag lengkap dengan hati-hati, keseimbangan kekuatan secara efektif dimanfaatkan untuk aplikasi, memungkinkan untuk menyesuaikan desain untuk persyaratan utama dalam hal membaca jangkauan tag. Daya rendah telah ditunjukkan, yang menjamin untuk biaya rendah, perangkat pasif kinerja tinggi, cocok untuk aplikasi komputasi di mana-mana.

\subsection{Teknik yang digunakan untuk meningkatkan kinerja teknologi sistem pervasif dalam domain logistik}

Dalam perkembangannya, teknologi seperti RFID dan wireless sensor networks mempunyai kelemahan dalam implementasi, untuk mengatasi masalah ini ditemukan beberapa penelitian yang membahas tentang teknik yang digunakan untuk meningkatkan kinerja teknologi tersebut. Di bawah ini adalah beberapa teknik yang digunakan untuk meningkatkan kinerja dari teknologi RFID dan wireless sensor networks.

\subsubsection{Teknologi RFID}

4.7.1.1. Smoothing Method (Zu, dkk., 2010)

Smoothing method merupakan metode yang digunakan untuk mengurangi kesalahan pada NLOS (Non Line of Sight Propagation). Metode ini digunakan untuk meningkatkan kinerja dari algoritma genetic. Selain itu metode ini memiliki tujuan untuk melakukan pengukuran waktu kedatangan(Time Of Arrival), sehingga dapat mengurangi dan menghambat efek NLOS. Algoritma genetik digunakan sebagai metode efisien untuk menyelesaikan persamaan nonlinear dari sistem. Tetapi, algoritma genetik memiliki kelemahan dalam proses penyelesaian masalah dalam konvergensi yang rendah dan konvergensi yang prematur.

Tahapan proses dalam smoothing data adalah sebagai berikut: (1) Readers menerima sinyal dari tag, (2) Pengolahan data awal dan pemodelan, (3) Melakukan pengkodean secara nyata dan memulai langkah awal, (4) Menghitung masing-masing nilai, (5) Menemukan dua kondisi, (6) Jika iya akan mendapatkan hasil, (7) Jika tidak akan dilakukan pengacakandan ekstraksi serta menahan yang terbaik dari grup, (8) Dilakukan pengecekan dan operasi mutasi, setelah melakukan penghitungan dari setiap anggota dan melakukan leiminasi terhadap yang tidak diharapkan dari grup.

Hasil eksperimen menunjukan bahwa peningkatan algoritma genetik memiliki hal yang lebih baik dalam lokasi dan akurasi serta stabilitas. Algoritma genetik yang diperbaiki memiliki 
akurasi posisi yang lebih baik serta dengan dilakukannya metode smoothing dapat mengukur data lebih tepat dalam hal posisi.

\subsubsection{Cross protocol method (Ruta, dkk., 2008)}

Pendekatan ini di adopsi dari semantic web (SW) yang mempunyai tujuan untuk mendukung fleksibilitas dalam hal dinamis dan desentralisasi layanan yang mencakup protocol. Nama pendekatan ini adalah cross protocol approach. Cross protocol method digunakan dalam teknologi RFID. Pendekatan ini mengeksploitasi metadata terkait yang disimpan dalam tag RFID. Pendekatan ini memiliki dua level arsitektur: (1) Field layer. Dalam layer ini RFID digunakan, layer RFID memiliki interkoneksi readers dan tags. (2) Discovery layer. Dalam discovery layer terjadi komunikasi antara readers dan mobile host pada konteks nirkabel.

Dalam pendekatan atau metode ini mengambil anotasi semantik dari tags dalam jangkauan radio menggunakan RFID readers. Selain itu, RFID readers dapat otomatis menangani permintaan tanpa kabel. Hasil eksperimen didapatkan berdasarkan implementasi prototype. Dilakukan pengujian pada HP Ipaq 2210h PDA. Hasil menunjukkan secara keseluruhan memiliki respon yang bagus selama requester dan mobile directory berinteraksi berdasarkan parameter delay. Pendekatan dengan komposisi dan substitusi fitur serta mengoptimalkan kerangka dan algoritma untuk meningkatkan waktu respon akan disajikan dalam pekerjaan di masa depan.

\subsubsection{Teknologi Wireless sensor networks}

\subsubsection{Multi threshold algorithm for local event detection ( Zöller, dkk., 2011)}

Metode ini di terapkan dalam teknologi wireless sensor networks. Dalam metode ini diusulkan konsep untuk menyaring data lokal yang bertujuan untuk mengurangi jumlah transmisi data. Kontribusi dari metode ini adalah bahwa menyaring data lokal sukses direalisasikan. Metode ini dapat memberikan biaya yang rendah dan efisiensi energy dalam pengoperasiannya. Hasil simulasi didapatkan bahwa metode ini memiliki keunggulan dalam transmisi data dan konsumsi sumber daya.

\subsubsection{Kalman filter technique (Gholami, dkk., 2012)}

Kalman filter adalah metode untuk mengukur estimasi waktu. Dalam metode ini digunakan pengukuran secara serial atau berkala, juga dengan variasi yang acak. Kalman filter memberikan estimasi variabel yang lebih baik daripada pengukuran tunggal. Metode ini dapat di sebut juga LQE (Linear Quadratic Estimation).Terdapat dua tahapan dalam metode ini; Pertama, dalam tahapan prediksi teknik melakukan generate estimasi dari variabel yang sedang berjalan. Setelah hasil pengukuran diobservasi, estimasi ini dapat diperbaharui menggunakan rata-rata bobot. Untuk menggunakan Kalman Filter dibutuhkan informasi yang tepat mengenai lokasi, kecepatan dan akselarasi. Dalam kasus Gholami, dkk. (2012) Kalman Filter digunakan untuk memprediksi estimasi objek bergerak yang melintas dengan kecepatan dan percepatan yang berbeda.

\section{Diskusi dan Isu Terkait \\ 5.1. Diskusi}

Penggunaan teknologi dalam komputasi pervasif semakin meningkat. Teknologi RFID (Radio Frequency Identification), teknologi WSN (Wireless Sensor Networks), dan teknologi hybrid adalah teknologi canggih yang digunakan dalam komputasi pervasif. Dengan meningkatknya tingkat kegunaan teknologi, teknologi tersebut diterapkan dalam berbagai bidang seperti health monitoring dan assistance, gaming, smart home serta transportasi dan logistik. Dari hasil sintesis penelitian ditemukan bahwa teknologi RFID lebih banyak digunakan dalam beberapa bidang kehidupan dan penggunaan teknologi RFID diperkirakan semakin meningkat di masa depan. Khususnya untuk bidang logistik, teknologi UHF RFID lebih cocok digunakan dalam aplikasi untuk melacak rantai pasokan dibandingkan dengan lainnya (LF, HF, dan Microwave) (Marinagi, dkk., 2013). Teknologi UHF (Ultra High Frequency) memiliki 
kisaran 860-960 MHz. UHF readers RFID tertanam dan lebih kecil di dalam kartu compact flash. Sehubungan dengan fungsi pembaca (reader) UHF RFID dapat membaca ID yang unik, membaca suhu dari jarak jauh, dan menentukan kecepatan dan arah perjalanan. Penggunaan teknologi hybrid seperti integrasi RFID ke dalam teknologi wireless sensor network disajikan dalam Zhang, dkk. (2006). Visi di masa depan adalah untuk menggabungkan lingkungan mereka dalam rangka untuk meningkatkan kinerja teknologi. Untuk menerapkan teknologi canggih dengan performa maksimal membutuhkan sesuatu untuk memperbaiki teknologi tersebut. Ada beberapa teknik untuk meningkatkan kinerja teknologi, seperti teknologi RFID dalam Ruta, dkk. (2008), Zu, dkk. (2010), dan teknologi wireless sensor network dalam Gholami, dkk. (2012) dan Zöller, dkk. (2011).

\subsection{Isu Keamanan}

Hampir semua makalah yang telah ditinjau telah menyajikan masalah keamanan. Hal ini disebabkan aspek keamanan merupakan bagian yang penting dalam sistem terdistribusi pervasif. Teknologi RFID menggunakan gelombang radio untuk mengidentifikasi objek. Dalam penerapannya teknologi RFID rentan terhadap serangan melalui saluran komunikasi. Hal ini mengakibatkan sistem keamanan dan privasi akan terancam. Untuk melindungi dan menjaga teknologi RFID dibutuhkan perlindungan yang kuat. Sistem RFID memiliki tiga komponen utama termasuk tag, reader, dan back-end database. Ancaman dalam sistem RFID berdasarkan komponen dikelompokkan sebagai dua bagian, bagian pertama untuk tag dan komponen reader dan bagian kedua untuk komponen back-end database. Dalam hal ini ancaman bisa datang dari pihak ketiga seperti ancaman man in the middle attack. Ancaman untuk tag dan reader seperti penyadapan, tag kloning, tag tracing, dan pembalasan serangan. Sedangkan, ancaman untuk komponen back-end database sebagai contoh adalah serangan virus. Dalam hal pembahasan hanya disajikan masalah tentang ancaman untuk tag dan reader di RFID.

Berkaitan dengan tag dalam teknologi RFID, sering dijumpai ancaman seperti pembacaan scanning tag pada produk. Hal ini berbahaya bagi pelanggan dalam pembelian produk yang menggunakan tag RFID. Tag blocker digunakan untuk melindung pelanggan dalam masalah ini. Tag blocker adalah solusi dengan biaya rendah dan lebih baik dari solusi lain. Namun, tag blocker jika disalahgunakan dapat menyebabkan serangan yang merusak komunikasi antara tag dan reader. Terkait dengan masalah ini, dalam Wang, dkk. (2013) disajikan protocol untuk menandai deteksi. Hasil penelitian tersebut diperoleh bahwa protokol dapat mengurangi waktu deteksi sebanyak $90 \%$ jika dibandingkan dengan metode lain (state of the art detection method).

Untuk mengatasi ancaman seperti penyadapan, tag cloning, dan serangan replay dapat menggunakan teknik enkripsi. Selain itu, dapat digunakanpembatasan jarak antara tag dan reader. Teknik kriptograpi yang digunakan untuk melawan serangan relay, skema yang diusulkan dalam Gao, dkk. (2010) menghasilkan sesuatu dalam kunci untuk melawan serangan relay. Dalam Khedr (2013) disajikan skema sederhana yang murah, skala keamanan bergantung pada fungsi hash satu arah dan sinkronisasi informasi yang rahasia. Ada dua langkah dalam skema ini mencakup otentikasi timbal balik antara server back-end dan tag, serta server backend untuk menyelesaikan proses otentifikasi. Skema yang diusulkan memiliki kemampuan untuk menolak upaya seperti tag cloning, tag tracing, eavesdropping, dan reply attacks. Metode kunci hash acak pada Jin, dkk. (2011) ditingkatkan untuk beberapa reader dan sejumlah besar tag. Di sisi lain, ada teknik otentikasi untuk melawan ancaman. Banyak protokol otentikasi RFID yang diusulkan untuk memberikan privasi yang kuat bagi pemilik tag. Selain itu, banyak kerangka kerja untuk menganalisis keamanan dan privasi tetapi tidak diusulkan ke dalam sistem RFID offline. Dalam Kardaş, dkk. (2012) membahas sistem RFID offline, mengusulkan protokol otentikasi efisien RFID. Dalam protokol ini penggunaan fungsi unclonable fisik (PUFS) dan hal yang merusak privasi diberikan oleh protokol ini untuk menandai pemilik dari serangan. 


\section{Kesimpulan dan penelitian masa mendatang}

Studi literatur ini bertujuan untuk mengidentifikasi dan menganalisis teknologi yang digunakan dalam penelitian sistem terdistribusi pervasif khususnya dalam domain logistik antara tahun 2003 sampai dengan 2013. Selain itu juga untuk mengidentifikasi teknik untuk meningkatkan kinerja (improvement) teknologi yang digunakan. Didapatkan 27 penelitian sistem terdistribusi pervasif yang dipublikasi antara Januari 2003 dan Desember 2013. Studi literatur sistematis merupakan sebuah proses mengidentifikasi, mengevaluasi dan menafsirkan semua bukti penelitian untuk menjawab rumusan masalah yang meliputi cakupan topik atau fenomena yang menarik.

Berdasarkan hasil studi literatur didapatkan hasil bahwa penggunaan parameter real time paling banyak digunakan dalam literatur yakni untuk teknologi RFID sebanyak empat makalah $(14,8 \%)$, WSN tiga makalah $(11,1 \%)$, dan teknologi hybrid sebanyak satu makalah $(3,7 \%)$. Berdasarkan hasil pemetaan literatur yang di review didapatkan bahwa RFID, Wireless Sensor system, dan kombinasi antara Wireless Sensor system dengan RFID (hybrid) adalah teknologi yang digunakan untuk memantau rantai transportasi. Studi yang membahas teknologi RFID berjumlah sekitar delapan penelitian (50\%), Wireless sensor network enam penelitian $(37,5 \%)$ dan dua penelitian (12,5\%) membahas penggabungan teknologi (hybrid). Jadi, dapat disimpulkan bahwa RFID (Radio Frequency IDentification) adalah teknologi yang paling sering digunakan untuk memantau rantai transportasi.

Dalam implementasinya, teknologi yang digunakan untuk memantau rantai transportasi logistik memiliki kelemahan dan membutuhkan teknik untuk menyelesaikan masalah yang terjadi. Berdasarkan hasil review ditemukan beberapa teknik seperti metode smoothing, metode cross protocol, algoritma multithreshold, dan teknik Kalman Filter. Dalam studi selanjutnya akan membahas lebih banyak teknologi dan teknik yang digunakan dalam sistem terdistribusi pervasif tidak hanya dalam domain logistik tetapi mencakup domain-domain lainnya seperti Health monitoring dan assistance, gaming, serta smart home.

\section{Referensi}

Cao, Y. \& Zhang, J., 2011. Real-time traffic information collecting and monitoring system based on the internet of things. 2011 6th International Conference on Pervasive Computing and Applications, pp.45-49.

Chandrasekaran, S. \& Ravi, H., 2010. A fault tolerant pervasive model for intelligent transport system. 2010 International Conference on Computer and Communication Technologies in Agriculture Engineering, pp.1-5.

Doss, R., Zhou, Wanlei., Sundaresan, Saravanan., Yu, Shui., \& Gao, Longxiang., 2012. A minimum disclosure approach to authentication and privacy in RFID systems. Computer Networks, 56(15), pp.3401-3416.

Ferscha, A., 2012. 20 Years Past Weiser: What's Next? IEEE Pervasive Computing, 11(1), pp.52-61.

Gao, A., Wei, W. \& Shi, W., 2010. Efficient Password-Proven Key Exchange Protocol against Relay Attack on Ad Hoc Networks. 2010 IEEE Asia-Pacific Services Computing Conference, pp.469-475.

Gholami, M., Cai, N. \& Brennan, R.W., 2012. Evaluating alternative approaches to mobile object localization in wireless sensor networks with passive architecture. Computers in Industry, 63(9), pp.941-947.

He, L., Deng, Z., \& Huang, J. 2009. Navigation and communication platform for on board unit of logistics traffic. 2009 Joint Conferences on Pervasive Computing (JCPC), pp.305308.

Jin, B. \& Jin, H., 2011. Security Analysis of RFID based on Multiple Readers. Procedia Engineering, 15, pp.2598-2602. 
Kardaş, Suleyman., Celik, Serkan., Yildiz, Muhammet., \& Levi, Albert., 2012. PUF-enhanced offline RFID security and privacy. Journal of Network and Computer Applications, 35(6), pp.2059-2067.

Khedr, W.I., 2013. SRFID: A hash-based security scheme for low cost RFID systems. Egyptian Informatics Journal, 14(1), pp.89-98.

Kitchenham, B. \& Charters, S., 2007. Procedures for Performing Systematic Literature Reviews in Software Engineering. Keele University \& Durham University, UK.

Marchese, M. 2010. Wireless pervasive networks for safety operations and secure transportations. In Wireless Pervasive Computing (ISWPC), 2010 5th IEEE International Symposium on (pp. 226-231). IEEE.

Marinagi, C., Belsis, P. \& Skourlas, C., 2013. New Directions for Pervasive Computing in Logistics. Procedia - Social and Behavioral Sciences, 73, pp.495-502.

Martínez-Sala, A. S., Egea-López, E., García-Sánchez, F., \& García-Haro, J., 2009. Tracking of Returnable Packaging and Transport Units with active RFID in the grocery supply chain. Computers in Industry, 60(3), pp.161-171.

Raychoudhury, V., Cao, J., Kumar, M., \& Zhang, D., 2013. Middleware for pervasive computing: A survey. Pervasive and Mobile Computing, 9(2), pp.177-200.

Ricci, A., Grisanti, M., Munari, I. D., \& Ciampolini, P., 2009. Improved Pervasive Sensing With RFID: An Ultra-Low Power Baseband Processor for UHF Tags. IEEE Transactions on Very Large Scale Integration (VLSI) Systems, 17(12), pp.1719-1729.

Ruta, M., Di Noia, T., Di Sciascio, E., Piscitelli, G., \& Scioscia, F., 2008. A Semantic-Enabled Mobile Directory Service for RFID-Based Logistics Applications. 2008 IEEE International Conference on e-Business Engineering, pp.333-340.

Saha, D. \& Mukherjee, A., 2003. Pervasive computing: a paradigm for the 21 st century. Computer, 36(3), pp.25-31.

Sardroud, J.M., 2012. Influence of RFID technology on automated management of construction materials and components. Scientia Iranica, 19(3), pp.381-392.

Tiešytė, D., \& Jensen, C. S. 2007. Challenges in the tracking and prediction of scheduledvehicle journeys. In Pervasive Computing and Communications Workshops, 2007. PerCom Workshops' 07. Fifth Annual IEEE International Conference on (pp. 407-412). IEEE.

Wang, F., Xiao, B., Bu, K., \& Su, J., 2013. Detect and identify blocker tags in tree-based RFID systems. 2013 IEEE International Conference on Communications (ICC), pp.21332137.

Wang, W. \& Fan, S., 2009. RFID technology application in container transportation. 2009 Joint Conferences on Pervasive Computing (JCPC), pp.639-642.

Woo, S. H., Choi, J. Y., Kwak, C., \& Kim, C. O., 2009. An active product state tracking architecture in logistics sensor networks. Computers in Industry, 60(3), pp.149-160.

Xu, X., Gu, L., Wang, J., \& Xing, G. 2010. Negotiate power and performance in the reality of RFID systems. In Pervasive Computing and Communications (PerCom), 2010 IEEE International Conference on (pp. 88-97). IEEE.

Ye, J., Dobson, S. \& McKeever, S., 2012. Situation identification techniques in pervasive computing: A review. Pervasive and Mobile Computing, 8(1), pp.36-66.

Zhang, L. \& Wang, Z., 2006. Integration of RFID into Wireless Sensor Networks: Architectures, Opportunities and Challenging Problems. 2006 Fifth International Conference on Grid and Cooperative Computing Workshops, pp.463-469.

Zhang, T., Luo, Z., Wong, E. C., Tan, C. J., \& Zhou, F., 2008. Mobile Intelligence for Delay Tolerant Logistics and Supply Chain Management. 2008 IEEE International Conference on Sensor Networks, Ubiquitous, and Trustworthy Computing (sutc 2008), pp.280-284.

Zöller, S., Kaiser, A., Reinhardt, A., Schulte, S., \& Steinmetz, R., 2011. A multi-threshold approach for efficient and user-centric event transmission in logistics wireless sensor networks. 2011 6th International Conference on Pervasive Computing and Applications, pp.435-442. 
$\mathrm{Zu}, \mathrm{Q} . \& \mathrm{Wu}, \mathrm{T} ., 2010$. Application of radio frequency positioning technology in TDOA system based on improved genetic algorithm. 5th International Conference on Pervasive Computing and Applications, pp.167-171. 